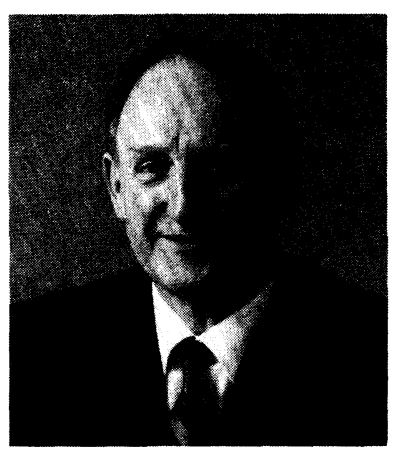

\section{Special Issues, Special Sections, and Related Topics}

Optical Engineering has made a point of providing its readers with a feature that gathers together a number of papers that are closely related on a timely topic of importance in optical engineering. As you know, these groupings of papers do not just happen - they are planned and scheduled. One of my responsibilities as Editor is to choose suitable topics and select a Guest Editor for each. Not incidentally, I am always interested in suggestions for both topics and Guest Editors.

Currently, the journal contains about 25 papers a month. If all the papers in a particular issue are devoted to that topic, then the issue is truly a special issue of the journal even though it is one of the regular monthly issues. This does not happen very often (in fact, it has not happened yet during my tenure). Usually the papers on the selected topic are grouped together in a "special section" at the front of that particular issue. Whether it is a special issue or a special section, it is preceded by an editorial prepared by the Guest Editor.

Once a special section is arranged and a Guest Editor chosen, we announce the topic in the editorial schedule, which appears immediately following my editorial in each issue. The Guest Editor will actively procure papers as well as receive those that are submitted in response to the information in the editorial schedule. The Guest Editor's task is to obtain a well-rounded set of papers that represents the state of the art of that topic. Often a special will be stimulated by one of the conferences run by SPIE-The International Society for Optical Engineering. However, it is not sufficient to include only papers from a conference, and those papers that are selected must meet the guidelines set forth for the publication of proceedings papers. ${ }^{1}$

The Guest Editor is responsible for receiving the submitted manuscripts, logging in the date received, and having the papers reviewed by at least two experts in the field. The Guest Editor returns papers to their authors if revisions are required by the reviewers. As the penultimate step, the Guest Editor checks that the manuscripts follow the guidelines set out in the "Information for Contributors" that appears at the end of each issue of Optical Engineering. To assist in this task, we provide the Guest Editor with a checklist, which includes such items as format, quality of illustrations, keywords, format of references, figure and table captions, authors' biographies and photographs, and publication charges. The final step for the Guest Editor is to mail the original manuscript with the checklist to me for formal acceptance. After a final check on the manuscript, I forward it to the managing editor's office in Bellingham, where the journals staff does the production work to turn out the issue.

So how well does this process work? Since I became Editor starting with the January 1991 issue, we have published some 13 special sections in the journal. These special sections have contained a total of 173 papers for an average section size of 13.3 papers. Of the 173 papers, 40 have been published in a different form in SPIE's unrefereed proceedings.

We look forward to bringing you future special issues and special sections and maybe one day even a "special supplement" to the journal. However, these can only happen with the dedicated efforts of our Guest Editors. I owe them a special thanks for what they do to help me, and I also pass on a thank you to them from all our readers. Thank you, Guest Editors.

Brian J. Thompson Editor

\footnotetext{
${ }^{1}$ B. J. Thompson, “Editorial," Opt. Eng. 31(6), 1141 (1992).
} 
October 1992

Acousto-Optics

Ting-Chung Poon

Virginia Polytechnic Institute and State University

Bradley Department of Electrical Engineering

Optical Image Processing Laboratory

Blacksburg, VA 24061

703/231-4876 • 703/231-3362 FAX

\section{December 1992}

Automatic Target Recognition

Firooz Sadjadi

Systems and Research Center

Honeywell Inc.

3660 Technology Drive

Minneapolis, MN 55418

$612 / 782-7543 \cdot 612 / 782-7438$ FAX

\section{January 1993}

Optical Research in Asia

Chung J. Kuo

National Chung Cheng University

Department of Electrical Engineering

Chiayi, Taiwan 62107

886-5-272-0411, ext. 6210 • 886-5-272-0862 FAX

Toshimitsu Asakura

Hokkaido University

Research Institute of Applied Electricity

Sapporo, 060 Japan

81-11-716-2111 • 81-11-758-3173 FAX

Yong H. Lee

KAIST Department of Physics

Yusung-Ku, Taejon, Korea

82-42-829-2536 - 82-42-861-1458 FAX

Run W. Wang

Shanghai Institute of Optics and Fine Mechanics

P.O. Box 800-211

Shanghai, 201800 China

\section{March 1993}

Optical Fiber Reliability II

Hakan H. Yuce

Bellcore

445 South Street

Morristown, NJ 07962

201/829-4945 • 201/267-9753 FAX

Charles R. Kurkjian

AT\&T Bell Laboratories

600 Mountain Avenue

Murray Hill, NJ 07960-1910

908/582-2378 • 908/582-2783 FAX

\section{April 1993}

Emerging Optoelectronic Technologies

Vijai K. Tripathi

Oregon State Univeristy

Dept. of Electrical and Computer Eng.

ECE Building 220

Corvallis, Oregon 97331-3211

503/737-3617 • 503/737-1300 FAX

May 1993

Phase Contrast Microscopy

Maksymilian Pluta

Institute of Applied Optics

ul. Kamionkowska 18

03-805 Warszawa, Poland

4822184405 or 4822184497

48221332 65 FAX

Manuscripts due Oct. 1, 1992.
June 1993

From Numerical to Symbolic Image Processing: Systems \& Applications

G. Vernazza

Dipartimento di Ingegneria Biofisica ed Elettronica Universita degli Studi di Genova

Via Opera Pia, 11a

16145 Genova, Italy

+39 10 353-2755 • +39 10353-2777 FAX

Manuscripts due Oct. 15, 1992.

\section{July 1993}

Visual Communication and Image

Processing IV

Cheng-Tie Chen

Bellcore

445 South St.

Morristown, NJ 07962

201/829-5151 • 201/829-5884 FAX

Hsueh-Ming Hang

Center for Telecommunication Research

National Chiao-Tung University

Hsinchu, Taiwan

$+886 / 35-712121 \times 3298 \cdot+886 / 35-723283$ FAX

Kou-Hu Tzou

COMSAT Labs.

22300 Comsat Drive

Clarksburg, MD 20871

301/428-4663 - 301/428-7747 FAX

Manuscripts due Dec. 1, 1992.

August 1993

Electro-Optical Flight Systems

Amar Choudry

Science and Technology Corporation

101 Research Drive

Hampton, VA 23666

804/865-1894

Manuscripts due Jan. 1, 1993.

September 1993

Optical Science and Engineering in Canada

C.P. Grover

National Research Council

Institute for National Measurement Standards

Ottawa, Canada K1A OR6

613/993-2098 • 613/952-1394 FAX

Manuscripts due Feb. 1, 1993.

October 1993

Microlithography

James R. Sheats

Hewlett-Packard Company

2500 Deer Creek Road

Palo Alto, CA 94304-1392

415/857-5987 • 415/857-6241 FAX

Manuscripts due March 1, 1993.

November 1993

Acquisition, Tracking, and Pointing

Mohammed A. Karim

University of Dayton

Center for Electro-Optics

300 College Park

Dayton, Ohio 45469-0227

513/229-2241 • 513/229-3433

Manuscripts due April 1, 1993.

\section{December 1993}

Magnetospheric Imagery and Atmospheric Remote Sensing

Supriya Chakrabarti

Boston University

Center for Space Physics

725 Commonwealth Avenue

Boston, MA 02215

E-mail: supc@bu-ast.bu.edu

617/353-5990 • 617/353-6463 FAX

Manuscripts due May 1, 1993.

January 1994

Infrared Technology

Marija S. Scholl

Jet Propulsion Laboratory

California Institute of Technology

4800 Oak Grove Drive

Pasadena, CA 91009-8099

818/354-2313 • 818/393-6105 FAX

Manuscripts due June 1, 1993.

February 1994

Optical Interconnects and Packaging

Sing Lee

University of Califomia/San Diego

E\&CE Department

La Jolla, CA 92093-0407

619/534-2413 • 619/534-1225 FAX

Manuscripts due July 1, 1993.

March 1994

High Heat Flux Optical Engineering

Ali M. Khounsary

Argonne National Laboratory

Advanced Photon Source, APS 360

9700 South Cass Avenue

Argonne, IL 60439-4814

708/252-3384 • 708/252-3222 FAX

Manuscripts due Aug. 1, 1993.

April 1994

Micro-Optics

Chandrasekhar Roychoudhuri

University of Connecticut at Storrs

Photonics Research Center

MS-157, Room 312

260 Glenbrook Road

Storrs, CT 06269-3157

203/486-4816 • 203/486-3789 FAX

Manuscripts due Sep. 1, 1993.

June 1994

Optical Science \& Engineering in India

Rajpal S. Sirohi

Indian Institute of Technology

Applied Optics Laboratory

Physics Department

Madras-600 036, India

044-2351365 ext. $221 \cdot 044-2350509$ FAX

Manuscripts due Nov. 1, 1993. 